\title{
L'impacte familiar que suposa tenir un fill o una filla amb el trastorn d'Asperger
}

\author{
IRENE GARCIA MOLINA \\ 106890@uji.es \\ ClARA ANDRÉS ROQUETA \\ candres@uji.es \\ Rosa Ana Clemente Estevan \\ clemente@uji.es
}

\section{Resum}

L'objecte d'estudi que es presenta a continuació és l'impacte familiar, a través de les respostes de 10 famílies amb fills amb el trastorn d'Asperger; tots ells de l'Associació Asperger de Castelló.

Es tracta d'un estudi que utilitza com a instrument un qüestionari adaptat de Donenberg i Baker. A més, aquest també conté respostes qualitatives en molts dels seus ítems.

Els resultats semblen indicar que, el major impacte familiar vesa sobre l'àmbit econòmic, seguint-lo de ben a prop l'emocional i actitudinal, i en últim Iloc, l'àmbit social. S'ha realitzat una anàlisi no paramètrica, servint la $U$ de Mann-Whitney amb altres variables tals com: Edat, Estat civil i Grau d'afectació de l'Asperger. S'hi destaca que només el grau d'afectació de l'Asperger (aquell grup més afectat dintre l'espectre autista) té una tendència significativa amb els Sentiments i actituds d'aquests pares. Per últim, en referència a les respostes qualitatives, es troben les situacions i els perquès més recurrents en les diferents respostes obertes; aquelles que els provoquen més estrès i també les de més felicitat.

Paraules clau: Asperger, DSM, impacte familiar, Trastorn Generalitzat del Desenvolupament.

\section{Abstract}

The study presented below shows the impact in the family based on the responses of 10 families with children presenting Asperger's Disorder, members of the Asperger's Association of Castellon.

This study used a questionnaire adapted from Donenberg and Baker, containing qualitative responses. 
The results suggest that the greatest impact is produced on the family economy, closely followed by emotional and attitude issues, and lastly, on the social life. In addition, has been performed a non-parametric analysis, using the Mann-Whitney $\mathrm{U}$, including other variables such as: age, marital status and level of involvement of the Asperger. It is remarkable that the severity of Asperger (those in the most affected group within the autistic spectrum) has a significant trend with the feelings and attitudes of the parents studied. Finally, regarding the qualitative responses, the most common answers are related to situations that caused stress and happiness.

Keywords: Asperger, DSM, family impact, Pervasive Developmental Disorder (PDD).

\section{Introducció}

Quan un nounat arriba a la família, tot és alegria i felicitat. Açò, però, canvia la vida dels progenitors, i aquests, transformen la seva vida per dedicar-li-la, quasi per complet (almenys durant els seus primers anys de vida) al nou membre de la família. Atès però, si a més, aquest nen o nena presenta alguna problemàtica, l'impacte que açò provoca en la família és molt major, i pot alterar-ne diferents àrees, i per un major període temporal.

És aquest, el cas de les famílies amb algun nen o nena amb la síndrome d'Asperger. Una síndrome, relativament "nova» dintre dels Trastorns del Desenvolupament; incorporada per primera volta en el Manual estadístic de diagnòstic de trastorns mentals (DSM-IV), en 1994.

Qui té dit trastorn, es distingeix de la població típica, per la seva limitada interacció social i afectiva, els seus interessos restringits i repetitius; així com els seus problemes de comunicació, les estereotípies i rituals (Berney, 2004).

I açò, a més d'afectar el propi individu, també afecta els seus contexts més immediats com ara la família.

Existeixen variables que es relacionen significativament amb la qualitat de vida, com són la salut física i la mental, tant en els pares amb infants amb el trastorn d'Asperger, com en els que els seus fills no tenen cap discapacitat (Lee et al., 2009). En dit estudi, també s'hi destaca, pel que fa als pares de nens amb Asperger, una relació significativa envers la salut física i variables com ingressos, nombre de fills i estrès; així com també en la salut mental amb les variables ingressos i estrés.

Altres estudis, comparen a més, aquest impacte, amb altres trastorns, com la Síndrome de Down. Sent els pares de nens amb autisme, els qui puntuen més alt en estrès. A més, en concret, les mares de nens amb autisme puntuen més alt que els pares, no trobant-se significació amb els pares de fills amb síndrome de Down o nens amb un desenvolupament típic (Drawoska y Pisula, 2010).

Tenint en compte la literatura, variables com ingressos, estrès i gènere, seran analitzades -entre d'altres- en el següent treball. L'impacte familiar d'un fill o filla amb Asperger és encara un estudi pilot, ja que la població és encara petita i la prova és un qüestionari adaptat.

La investigació aporta els resultats d'uns casos molt concrets i ens dóna una petita visió de l'impacte que suposa tenir un fill o filla amb Asperger; des de les àrees de Sentiments i actituds, Vida social i Economia; del Qüestionari d'Impacte Familiar adaptat de Donenberg i Baker, 1993.

Així, els objectius que es volen presentar en aquest article, són: 
- Conèixer l'impacte sobre la família, tenint com a referència nens típics d'edat, de nens i nenes amb Asperger, en les àrees de Sentiments $i$ actituds, Vida social i Economia; segons el Qüestionari d'Impacte Familiar adaptat de Donenberg y Baker, 1993.

- Conèixer quina de les tres àrees té més impacte per a les famílies: Sentiments $i$ actituds, Vida social i Economia; del Qüestionari d'Impacte Familiar adaptat de Donenberg i Baker, 1993.

- Conèixer les raons que provoquen la qualificació de gravetat o levitat de la resposta qualitativa per part dels pares i mares de nens i nenes amb Asperger.

- Conèixer si les variables edat, estat civil i grau d'afectació del trastorn són significatives respecte l'impacte familiar.

\section{Mètode}

L'objecte d'estudi en el següent article és l'impacte familiar a través de les respostes de pares i mares amb fills amb Asperger. Així doncs, els seus resultats no seran generalitzables, però a partir de la literatura i allò estudiat, s'extrauran una sèrie de conclusions envers l'impacte que aquests infants poden generar en l'àmbit familiar.

\section{Mostra}

La mostra per a dit estudi, es pren de famílies pertanyents a l'Associació Asperger CasteIló, les quals han respost voluntàriament al qüestionari. En total són deu famílies, dels voltants de Castelló, i que els seus fills participen en tallers dintre l'associació.

Pel que fa als nens i nenes amb Asperger, els situem dintre un rang d'edat de 5 anys, entre 5 i 9 anys, amb una mitjana de 7 . A més, hi ha una gran diferència pel que fa al gènere, sent 9 nens i 1 nena, -corroborant-se així, la proporció d'1 nena cada 4 nens (1: 4). Pel que fa al nombre de germans: 5 tenen un germà/germana més, 4 són fills únics i només un és de família nombrosa. En referència a la relació matrimonial, 3 parelles de 10, no viuen sota el mateix sostre.

En tots els casos, han sigut les mares les qui han respost el qüestionari, menys en un subjecte.

La duració de l'estudi ha sigut curta, ja que les famílies han emplenat en les seves cases el Qüestionari d'Impacte Familiar, i a les poques setmanes s'han tornat tots respostos.

\section{Instruments}

El Qüestionari d'Impacte Familiar és una adaptació feta pel Departament de Psicologia Evolutiva, Educativa, Social i Metodologia, del qüestionari de Donenberg i Baker, en 1993.

A més, per a dit estudi, s'han elegit només les 3 primeres categories del qüestionari original: Sentiments i actituds, Vida social i Economia.

A aquest qüestionari es respon mitjançant una escala tipo Likert, col-locant una marca en la casella corresponent: Quasi mai, Algunes voltes, Moltes voltes, Quasi sempre. Però a més, també es pot donar una resposta més oberta, ja que es deixen unes línies per si el pare o la mare vol respondre «En quines situacions?» o «Per què?». Donant-nos així, la possibilitat d'una millor valoració de cada àrea. Com ja s'ha explicat amb anterioritat, les àrees a estudiar en aquest qüestionari són: «Els seus sentiments i actituds cap al seu fill» (15 ítems), «L'impacte 
del seu fill sobre la vida social» (10 ítems), i «L'impacte del seu fill sobre la seva economia» (7 ítems). Amb preguntes referents a diferents sentiments que produeix el fill o filla, control de situacions, temps en família, amics, costs de diversos serveis...

La puntuació correspon al grau d'impacte familiar (de menys a més) que percep el pare o la mare. A més puntuació, més impacte familiar.

Amb totes aquestes dades, s'hi realitza l'anàlisi, mitjançant el programa estadístic SPSS, versió 21. Així, s'hi observen les dades, es calcula la puntuació de cada àrea i s'hi estableix en quina de les tres existeix més impacte. Més tard, mitjançant la $U$ de Mann-Whitney, s'hi estableix la significació de tres variables extretes de la mateixa informació, com són: edat, estat civil i grau d'afectació del trastorn.

\section{Resultats}

\section{Resultats generals}

Amb totes les dades recollides de les deu famílies, s'han extret les puntuacions totals, i s'han tansformat en una escala sobre 100. Els resultats han sigut els següents:

- Els seus sentiments i actituds cap al seu fill: 48.6

- L'impacte del seu fill sobre la seva vida social: 33

- L'impacte del seu fill sobre l'economia: 53.6

Per tenir una visió més general, vegeu la gràfica 1:

\section{Impacte familiar}

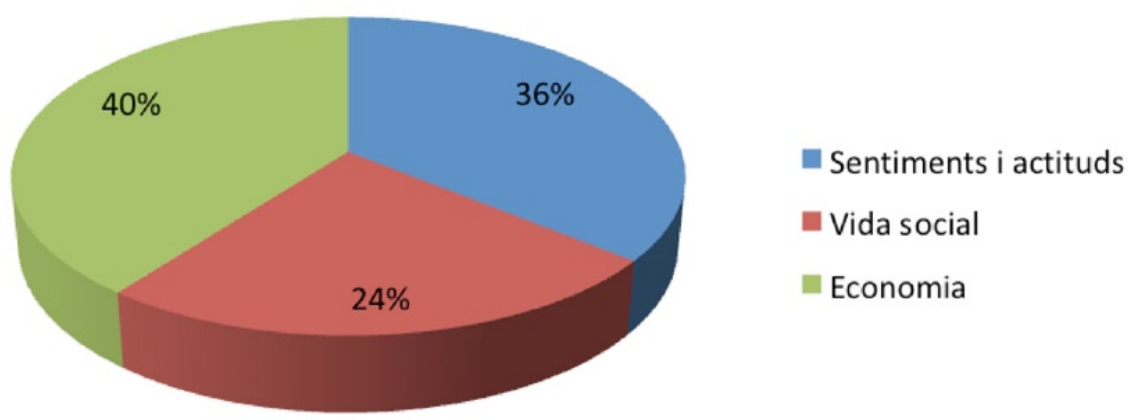

Gràfica 1: Impacte familiar

Com es detalla a la gràfica 1 , per als pares de dita mostra, el major impacte familiar incideix sobre l'àmbit econòmic, seguit de ben a prop per l'emocional i actitudinal, i en últim lloc, la vida social.

Així, més detalladament, observem dintre l'àmbit econòmic, que un dels ítems amb més puntuació ha sigut: 
31. «El cost dels serveis educatius i psicològics és major (comparat amb nens/nenes de la mateixa edat que el meu fill)».

Pel que fa a les àrees restants, es pot veure com l'impacte dels sentiments i actituds cap als fills, és alta i per tant, també l'hem de tenir en compte.

Els ítems amb puntuació més alta són:

7. «El comportament del meu fill em preocupa més (que nens o nenes de la seva mateixa edat...)».

10. «El meu fill em fa tenir més energies».

12. «El meu fill em fa sentir més segur com a pare».

També, en l'impacte del fill sobre la vida social, podem destacar l'ítem 22, que d'aquesta àrea és el més alt: «Necessite explicar més la conducta del meu fill a altres persones».

\section{Altres variables}

També s'ha realitzat una anàlisi de proves no paramètriques, amb la $U$ de Mann-Whitney, per grups d'edat, vida familiar i grau d'afectació de l'Asperger.

\section{Edat}

Pel que fa a les variables d'edat, s'han considerat 2 grups, de 5 a 6 anys, i de 7 a 9 anys; amb 5 subjectes en cadascun dels grups. Els resultats demostren que no hi ha significació en els tres àmbits del qüestionari.

Taula 1

Agrupacions per edat

\begin{tabular}{|c|c|c|c|c|}
\hline \multicolumn{2}{|c|}{ AGRUPACIÓ EDAT } & \multirow{2}{*}{$\begin{array}{r}\text { SUMA SENTIM. } \\
28,80(4,91)\end{array}$} & \multirow{2}{*}{$\begin{array}{c}\text { SUMA SOCIAL } \\
14,20(, 83)\end{array}$} & \multirow{2}{*}{$\begin{array}{c}\text { SUMA ECONOM. } \\
14,80(4,08)\end{array}$} \\
\hline 5-6 anys & $\begin{array}{c}\text { Mitjana } \\
\text { (Desv. Típ) }\end{array}$ & & & \\
\hline $7-9$ anys & $\begin{array}{c}\text { Mitjana } \\
\text { (Desv. Típ) }\end{array}$ & $29,60(8,04)$ & $12,20(2,58)$ & $15,20(2,48)$ \\
\hline $\begin{array}{l}\text { Prova U d } \\
\text { Mann- } \\
\text { Whitney }\end{array}$ & & 0,91 (n. s.) ${ }^{*}$ & 0,32 (n. s.) & 0,91 (n. s.) \\
\hline
\end{tabular}

*(n. s.) no significatiu 


\section{Estat civil}

Respecte a l'estat civil de les famílies, els resultats de la $U$ de Mann-Whitney, no han sigut significatius. S'especifiquen dos grups: parella (7 subjectes) i divorci (3 subjectes).

Taula 2

Agrupacions per estat civil

\begin{tabular}{lcccc}
\hline PARELLA & SUMA SENTIM. & SUMA SOCIAL & SUMA ECONOM. \\
\hline PARELLA & $\begin{array}{c}\text { Mitjana } \\
\text { (Desv. Típ) }\end{array}$ & $29,28(7,71)$ & $13,71(1,79)$ & $15,57(3,30)$ \\
$\begin{array}{c}\text { Mitjana } \\
\text { DIVORCI }\end{array}$ & $29,00(0,00)$ & $12,00(2,64)$ & $13,66(3,05)$ \\
$\begin{array}{l}\text { Provi U U de } \\
\text { Mann- } \\
\text { Whitney }\end{array}$ & 0,29 (n. s.) & 0,40 (n. s.) & 0,41 (n. s.) \\
\hline \hline
\end{tabular}

\section{Grau del trastorn. Grau d'afectació de l'Asperger}

Pel que fa a la gravetat de l'afectació de l'Asperger trobem dos grups, dividits entre el grup mesafectat: els infants cognitivament pitjor (més afectats dintre de l'espectre autista) que en són 3; i el grup menysafectat: els infants cognitivament millor (menys afectats dintre de l'espectre autista) que en són 7 . Els resultats apunten a una tendència significativa $(.08)$ en Sentiments i actituds, amb un major impacte en el grup 0, nens més afectats, que es decanten més cap a un Trastorn Generalitzat del Desenvolupament (menys Asperger), pel qual tindran majors dificultats socials, estereotípies, conductes de refús...

Taula 3

Agrupacions segons el grau d'afectació

\begin{tabular}{|c|c|c|c|c|}
\hline \multicolumn{2}{|c|}{ GRAU PATOLOGIA } & \multirow{2}{*}{$\begin{array}{c}\text { SUMA SENTIM. } \\
31,33(10,69)\end{array}$} & \multirow{2}{*}{$\begin{array}{c}\text { SUMA SOCIAL } \\
12,00(2,64)\end{array}$} & \multirow{2}{*}{$\begin{array}{r}\text { SUMA ECONOM } \\
15,33(2,88)\end{array}$} \\
\hline mesafectat & $\begin{array}{c}\text { Mitjana } \\
\text { (Desv. Típ) }\end{array}$ & & & \\
\hline menysafectat & $\begin{array}{c}\text { Mitjana } \\
\text { (Desv. Típ) }\end{array}$ & $28,28(4,27)$ & $13,71(1,79)$ & $14,85(3,53)$ \\
\hline $\begin{array}{l}\text { Prova U de } \\
\text { Mann- Whit- } \\
\text { ney }\end{array}$ & & $0,08(\mathrm{t})^{* *}$ & 0,40 (n. s.) & 0,72 (n. s.) \\
\hline
\end{tabular}

** $(\mathrm{t})$ tendència 
Malgrat que en les taules presentades apareix una tendència significativa en l'apartat de Sentiments $i$ actituds, bona part de la informació important en l'àmbit d'emocions i de vida social es troba en les respostes qualitatives. Aquestes, les trobem resumides en dos apartats:

«En quines situacions?» o «Per què?»

- Situacions pare/mare ho passa mal, estrès, preocupació:

Quan el nen és a l'escola, en la seva classe, llocs on hi ha gent davant que no el coneix (per exemple: la consulta del doctor), quan té una enrabiada, atacs d'ira, quan es tanca sobre si mateix, quan hi ha canvi de plans...

- Per què?

Perquè la gent no el coneix i el pot veure com el «bitxo raro», perquè a voltes sembla superdotat, i a voltes tonto, no sol prestar atenció, hi ha por a què no l'entenguen, que li coste fer amics, té moltes peculiaritats, perquè atabala els altres nens, perquè pot ser molt inoportú i molt cansat amb els seus temes o obsessions...

- Situacions pare/mare ho passa bé amb el seu fill, es diverteix, se sent bé...: a l'hora del bany, a l'hora de gitar-lo, d'alçar-lo als matins, i en el joc de tu a tu, quan són sols.

- Per què?

Perquè demostra el seu afecte, aconseguim millores, és més fàcil tot, em sent més estimada...

\section{Discussió i conclusions}

L'impacte familiar obtingut en aquest estudi, remarca l'econòmic, com l'àmbit que puntua més alt, sent dintre d'aquest, el cost en serveis educatius i psicològics, l'ítem més significatiu. L'impacte dels sentiments i actituds cap als fills, també és alt i, per tant, l'hem de tenir en compte; ja que l'estrès exerceix un efecte negatiu sobre el clima emocional del pare i la mare, i també sobre les relacions familiars i amistats, afectant així a altres àmbits de la família. Pel que fa a l'impacte en l'àmbit social, en aquest cas és menor; però cal recordar que aquest és un primer estudi, i els seus resultats no són generalitzables.

També cal remarcar la tendència a la significació en sentiments i actituds del grup de nens més afectats en l'autisme, als qui se'ls suposa una major mancança en relacions socials, amb una pitjor cognició. Aquest fet, afecta en un àmbit més personal, emocional, actitudinal de cada pare/mare d'aquest estudi, que es denota en les respostes qualitatives en les que expliquen les situacions i els perquès.

Per últim, referent a les respostes qualitatives, trobem que en aquests casos, existeixen uns trets comuns. En destaquem els següents:

La preocupació major per part d'aquests pares és en l'escola, la seva classe, el que la gent que no el coneix el vegi com el «bitxo raro», que no l'entenguen, que li coste fer amics, que pugui ser molt inoportú i molt cansat amb els seus temes o obsessions.

A més, la resposta que més s'ha repetit ha sigut que les mares gaudeixen més del seu fill durant el bany, a l'hora de gitar-lo i en el joc de tu a tu, quan són sols. El major estrès, és sobretot quan hi ha gent davant.

També trobem conductes més reivindicatives, del tipus que no volen amagar el seu fill/a i que la societat conegui aquest trastorn: «que "se n'assabenten", i l'entenguen». 
Aquestes diferents conclusions que, en general, no aconsegueixen un grau de significació estadística, es veuen empobrides per l'escàs nombre de subjectes de la mostra. Per tant, s'hi fa una reflexió a les limitacions que es tenen en els resultats. Aquests denoten un clar accent en economia que, en general, a Espanya preocupa a qualsevol pare i mare de família. Així doncs, una possible línia a investigar en aquestes primeres conclusions podria ser si l'impacte econòmic és certament el que més preocupa als pares d'un nen o nena amb Asperger, o si en canvi, ve agreujat per la crisi.

A més, les famílies també contribueixen econòmicament a l'Associació Asperger, cosa que també poden incloure dintre de costos educatius i psicològics, més tot el bagatge que se sol fer per consultes, psicòlegs i metges diversos per poder diagnosticar l'infant. Recordem que els nens tenen entre 5 i 9 anys, i molts tenen un diagnòstic de fa uns mesos.

Així doncs, es destaca com a possible línia d'investigació: l'ampliació de la mostra, i l'entrevista a les famílies, per indagar més en profunditat sobre les qüestions presentades; com per exemple, explorar sobre el tipus de família d'aquests nens, ja que en una gran part, hem esbrinat que és monoparental, cosa que econòmicament també contribueix a un empitjorament en aquest àmbit, per no disposar dels ingressos del pare en aquestes famílies («Sent que estic sola, en el meu cas, clar, com sóc família monoparental...»). També serien d'interès, els àmbits a analitzar del qüestionari, podent-los ampliar amb més categories, per a un major aprofundiment.

\section{Referències bibliogràfiques}

Berney, T. (2004). Asperger syndrome from child hood into adult hood. Advances in Psychiatric Treatment, 10, 341-351.

Dabrowska, A. \& Pisula, E. (2010). Parenting stress and coping styles in mothers and fathers of pre-school children with autism and Down syndrome. Journal of Intellectual Disability Research. Volumen 54 (3), 266-280.

Donenberg, G. \& Baker, B. L. (1993). The impact of young children with externalizing behaviors on their families. Journal of Abnormal Child Psicolygy, 21, 179-198.

Lee, G. K., Lopata C., Volker, M. A., Thomeer, M. L., Nida, R. E., Toomey, J. A. et al. (2009). Health-Related Quality of Life of Parents of Children With High-Functioning Autism Spectrum Disorders. Focus Autism Other Development Disabilities, 24 (4), 227-239. 